\title{
OPTIMIZATION OF COMPOSITE FIBER ORIENTATION ANGLE USING PARAMETRIC ANALYSIS IN ANSYS COMPOSITE PRE-POST
}

\section{S. BHANU MURTHY, M. AMARTHYA ESHWAR, SHAIK MASROOR AHMED, B. NAVEEN,}

\section{R. SACHIN \& R. ARUN}

Assistant professor, VNR Vignana Jyothi Institute of Engineering and Technology, Hyderabad, Telangana, India Research Scholar, VNR Vignana Jyothi Institute of Engineering and Technology, Hyderabad, Telangana, India Research Scholar, VNR Vignana Jyothi Institute of Engineering and TechnologyHyderabad, Telangana, India Research Scholar, VNR Vignana Jyothi Institute of Engineering and TechnologyHyderabad, Telangana, India Research Scholar, VNR Vignana Jyothi Institute of Engineering and TechnologyHyderabad, Telangana, India Research Scholar, VNR Vignana Jyothi Institute of Engineering and Technology, Hyderabad, Telangana, India

ABSTRACT
Curiosity and development have always been an integral part of human psychology. With the evolution in the industry,
optimization, credibility, and durability have become a prime focus which has led to the advancement in composite
materials in the material industry.
The behavior of composite materials under different loading conditions for different geometries cannot be
determined as in the similar way as conventional materials which lead to the anomaly about the type of composite
materials to be used. This work is concerned about the validation of the optimum orientation angle and to understand the
behavior of stress in each layer of a composite pressure vessel. Pressure vessel play a significant role in various industries
such as power plant, aeronautics, aerospace industry etc.
$\quad$ The fuel carried in aerospace application is also contained in pressure vessels. Therefore, the optimization of
pressure vessel using composite materials may help in weight reduction and provide greater efficiency to the rockets. The
failure linked to pressure vessel is a catastrophic failure. To understand the stress behavior and obtain optimum fiber
orientation angles, "Parametric Analysis" is used in ANSYS ACP. The geometry is then post analyzed to understand the
durability of the composite pressure vessel.
KEYWORDS: Composites, Composite Pressure Vessel, Fiber Orientation, Parametric Analysis, ANSYS ACP

Received: Jun 09, 2020; Accepted: Jun 29, 2020; Published: Aug 05, 2020; Paper Id.: IJMPERDJUN2020635

\section{INTRODUCTION}

The conventional materials like Iron, steel and its alloys, titanium, Aluminum etc. have a production process which releases a lot of toxic content which is harmful to the environment. Moreover, the manufacturing requires the acquiring of raw materials from its ore and then the need to process it. The energy required is also of huge amount to run a plant for producing industrial use metals. The behavior of all these ductile and brittle materials is studied and we get to know the how the material will perform on different load applications. The composite materials do not the share the similar behavioral pattern. The anisotropic behavior gives rise to complexity in determining the various material properties in different directions. Therefore, the variations in the properties in composite materials has become a primary focus for a lot of research engineering to develop materialswhich yield higher safety factors than compared to 
conventional method. $50 \%$ of the materials used in the aerospace industry is made of composites [1].

The study can bring help in manufacturing materials which are of minimal size but can bear unparallel load when compared to the conventional materials of same dimensions. The need to optimize materials might bring about a revolution through composite materials. The use of such materials for pressure vessels in rockets, submarines etc... might help in the efficiency and effectiveness of the process.

\section{PROCEDURES}

\subsection{ANSYS Modules}

\section{- Static Structural:}

Static structural is used to do analysis of components on which the load is not varying with time. In this module various analysis can be performed like stress analysis, strain analysis, displacement analysis etc. Component meshing and assigning of boundary conditions like the fixed supports, external loads are done before the analysis.

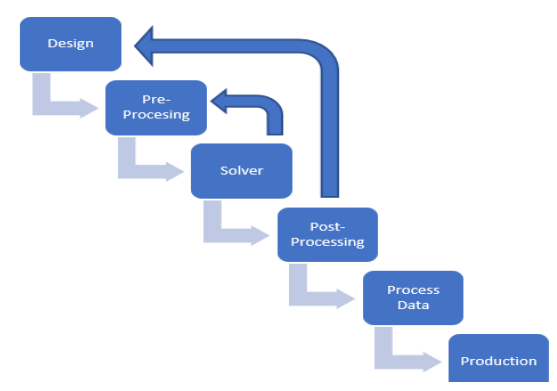

Figure 1: Flow Chart of ACP Process.

\subsection{Ansys Composite Pre-Post (ANSYS ACP):}

ANSYS ACP is used to do analysis on components made from composite materials. It has two sub modules namely 'ACP Pre' (Pre-processing) and 'ACP Post' (Post-processing). The 'ACP Pre' is used for defining the composite layup for the required geometry. 'ACP Post' is used to do analysis on the defined composite layup, layer by layer. It takes the necessary boundary conditions input from 'Static Structural' system.

\section{PARAMETRIC ANALYSIS:}

'Parametric Analysis' is a tool in ANSYS which is used to do 'iterative design' of components. Iterative design is defined as designing components by studying its behavior in various conditions and getting the optimum combination of strength and weight. Parametric analysis does analysis at various points without manually repeating all the processes.

\section{DESIGN CONSIDERATIONS}

A shell model is developed for the carbon epoxy pressure vessel as ANSYS ACP only accepts shell models to assign the composite material layers. End closures for the pressure vessel are made in CATIA V5 and titanium material is used. The input pressure is $10 \mathrm{MPa}$ 


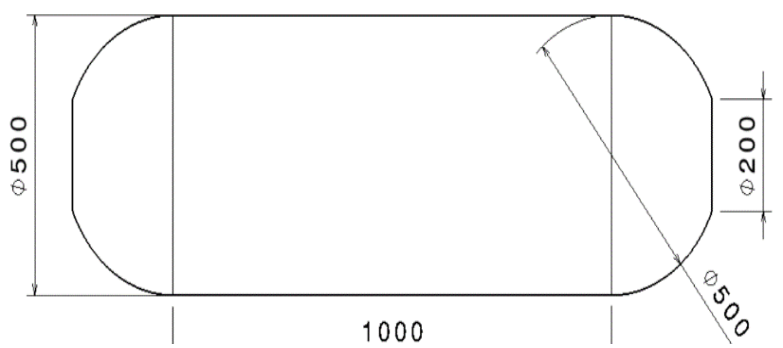

Figure 2: Dimension of Carbon Epoxy Pressure Vessel.

\section{PARAMETRIC ANALYSIS OF COMPOSITE PRESSURE VESSEL}

\subsection{D Modeling of Composite Pressure Vessel}

The 3D model for the composite pressure vessel is made using the 'Surface Design' module of CATIA V5 software under 'Mechanical'. Surface design is used because ANSYS ACP which generates the laminate layup for the pressure vessel accepts only shell components which means model with zero thickness.

\section{ANSYS ACP SETUP FOR COMPOSITE PRESSURE VESSEL}

\subsection{Meshing and Named Selections}

The surface model is imported in ANSYS ACP (Pre) module from the Engineering Data Sources and the required materials are added, i.e., Carbon Uni Directional Prepreg, Resin Epoxy material. Meshing is done on the surface model using the Face Meshing technique to get symmetrical mesh on the face for accurate results. Different named selection is given to the surface model faces which will be further used in the analysis.

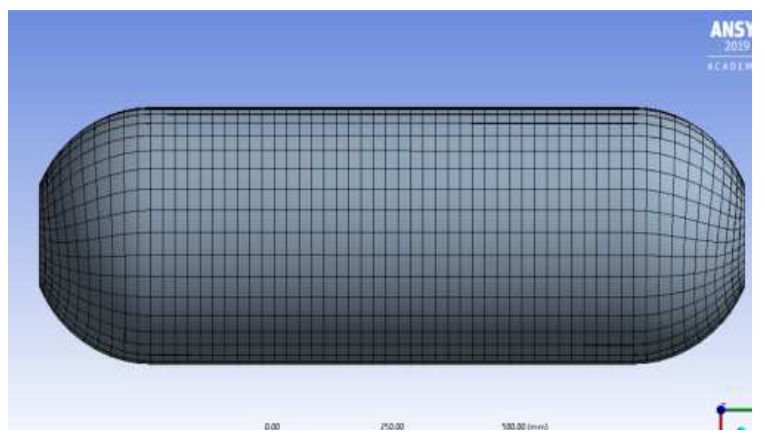

Figure 3: Surface Mesh of the Pressure Vessel.

\section{ANSYS COMPOSITE PRE-PROCESSING}

In the preprocessing the fiber orientation, number of layers and the thickness of the pressure vessel shell is given as input.

\subsection{Rosettes:}

Defining rosettes in a composite material component is very important because these rosettes define the fiber reference directions for the fiber to follow.

In the feature tree by right clicking on the Rosette option and selecting the Create Rosette option the Rosette properties dialog box opens.

Select the rosette type as a parallel rosette which is used for the reference fiber direction:

- The red arrow indicates the fiber direction. 
- The green arrow indicates the transverse direction

- The blue arrow indicates the normal direction.

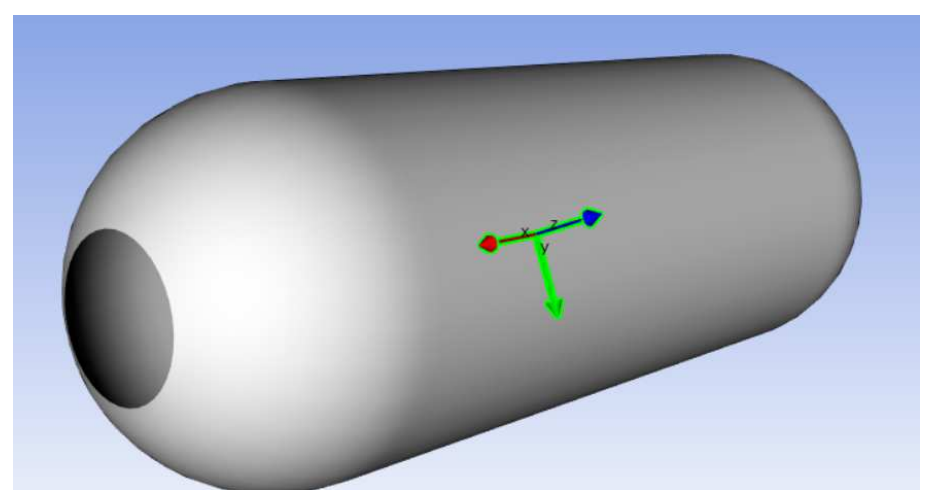

Figure 4: Various Axes in the Rosette.

\section{ORIENTED SELECTION SETS}

These are used to define the material addition direction for different elements. In case of the pressure vessel the direction is outward from the surface.

\section{MODELLING GROUPS:}

Modeling groups are used to layup the created fabrics onto the components and to stack them up in a particular ply orientation.

The stacking sequence of the initial estimated ply with odd symmetry is as follows:

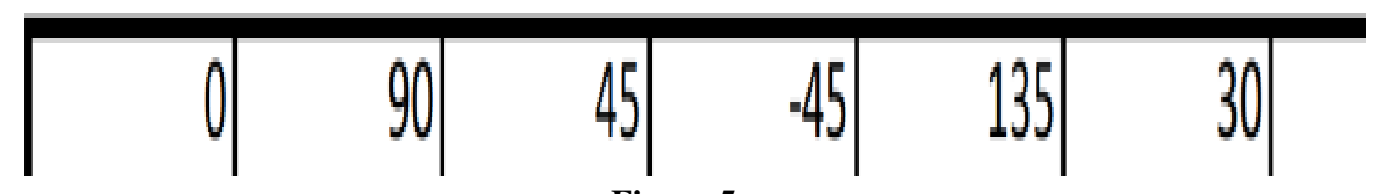

Figure 5

\section{SENSORS}

It is used to find the area and weight of the pressure vessel.

The weight of the pressure vessel was found to be $13.4 \mathrm{~kg}$ and the area was found to be $2285107.457 \mathrm{~mm}^{2}$

\section{PARAMETRIC ANALYSIS:}

\subsection{Assigning Parameters Procedure}

After the pressure vessel is made using the epoxy carbon composite to find the optimum ply angles and the optimum laminate parametric analysis is used.In the ACP feature tree right click on the parameters option and click on the create parameter button to create a parameter by choosing the required ply.

Then choosing the nature of the parameter i.e. Input or output. Ply angle is an input parameter. Thickness is also an input parameter. Repeat the above steps until all the layers of the composite laminate are assigned as parameters.For the output parameters static structural analysis is carried out and the stresses, deformation and safety factor are assigned as output parameters. 


\section{STATIC STRUCTURAL ANALYSIS FOR OBTAINING OUTPUT PARAMETERS:}

Static structural analysis is done on the vessel to get output parameters. The behavior of the initial estimated composite laminate is as follows:

Maximum Deformation: 3.0286mm, Equivalent Elastic Strain: 0.017859, Equivalent Stress: $867.96 \mathrm{MPa}$

Figure 6 shows from the above distributions it is clear that the pressure vessel with this laminate configuration is not suitable for bearing pressure of $10 \mathrm{MPa}$. So Equivalent stress and strain, total deformation and inverse reserve factor are selected as the output parameters.

So, in order to find the optimum laminate configuration laminate ply angles, must be changed and analysis must be done on these different angles to get an optimum result. This is obtained using parametric analysis.

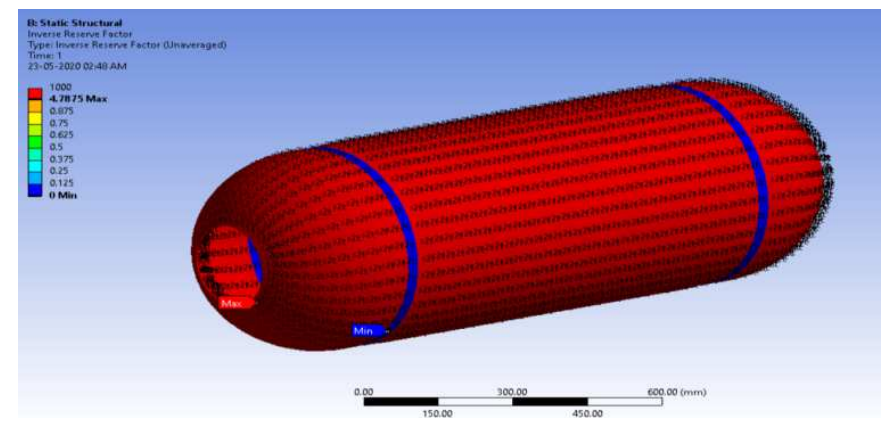

Figure 6: Inverse Reserve Factor.

\section{PROVIDING INPUT VALUES TO THE PARAMETER TABLE:}

All the input parameters and the output parameters are shown on the Outline Parameter Table.The values of various parameters called as 'Design Points' are entered in the design point table.

After the analysis is complete the design points are sorted in a way such that the least amount of deformation and least amount of stress induced ply is selected from this and further analysis is carried out on the selected ply orientation.

As shown in the above table the input and output values are given number and names for the parametric analysis. There can be new parameter additions as well, as per our required analysis. The number of iterations can be used to our advantage for analyzing the variation of the output parameters with the change in input parameters. Thus, parametric analysis helps us in the better understanding and is an amazing tool to carry out research work [2].

Table 1 shows in the table of design points the data enclosed in the red box is the input data that is the ply angles of different layers and thickness of each layer.

The data in the green box is the output results which include average equivalent stress, safety factor, total deformation, average equivalent elastic strain.

'DP0' in the parametric table represents the initial estimated ply orientation.

The ply orientations after the analysis are arranged in an ascending order so that the least induced stress ply orientation is on the top.

This is the optimum ply orientation from the 40 design points in the table. 
But the safety factor for this ply orientation is ' 0.40263 ' which is unsafe, so this ply orientation is further optimized by adding composite layers to the laminate to get a safety factor greater than one.

The various design points are tabulated with their outputs on the Table of design points which is as follows:

Table 1: Table of Design Points

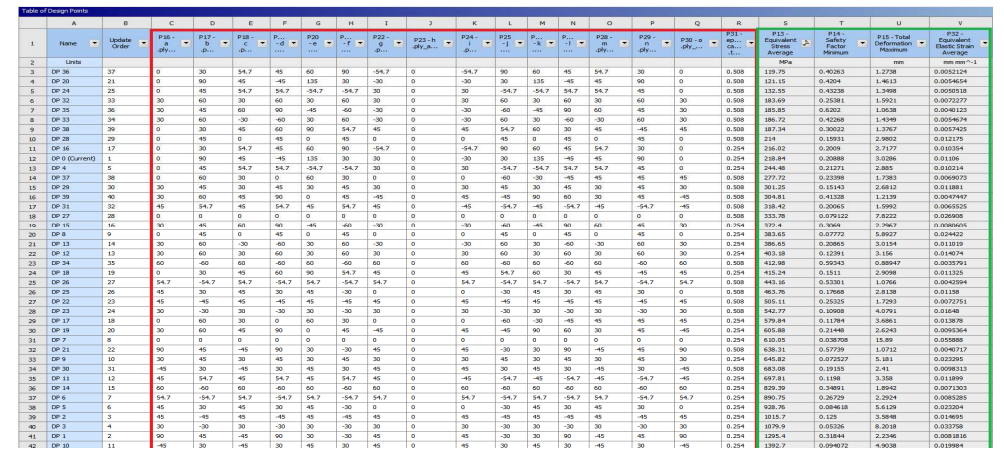

\section{LAYER OPTIMISATION FROM THE OUTPUT OF PARAMETRIC ANALYSIS}

The optimized layer from the parametric analysis is taken and opened in ACP Pre for further optimization. [3][4]

To achieve this, ten alternate layers are added to the composite laminate upon different iterations so that the obtained minimum safety factor was found out to be greater than one and IRF was found out to be 0.68.

Table 2

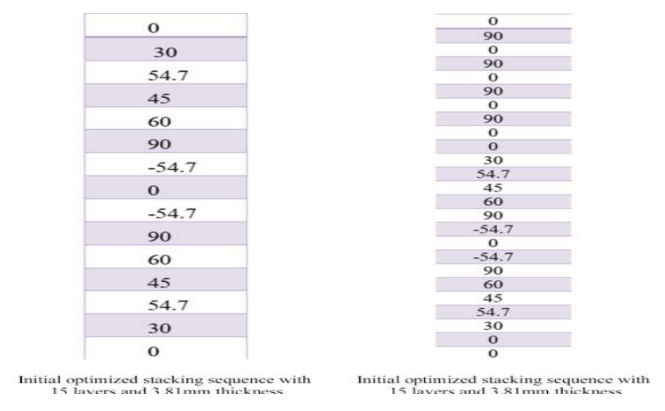

\section{RESULTS AND DISCUSSIONS:}

\subsection{Variation of Stress:}

From the result table the variation of the stress from the least induced stress to the highest varies as shown in the graph below.

Figure 7 shows this behavior is estimated as an exponential curve with the function $y=130.1 \mathrm{e}^{0.0553 \mathrm{x}}$.

Figure 8 shows the induced stress in the composite laminate varies exponentially which means that if proper fibre orientation is not given, the chance of failure in the pressure vessel is very high, which means that proper analysis is needed to be done before the manufacturing of the pressure vessel. 


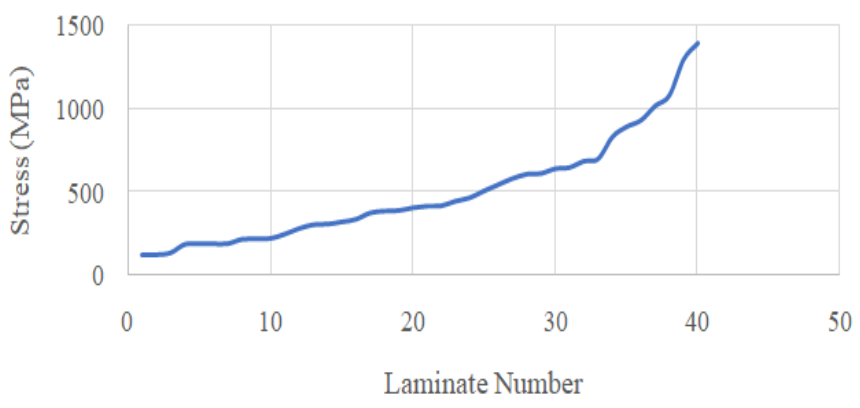

Figure 7: Stress Trend for Different Ply Orientations.

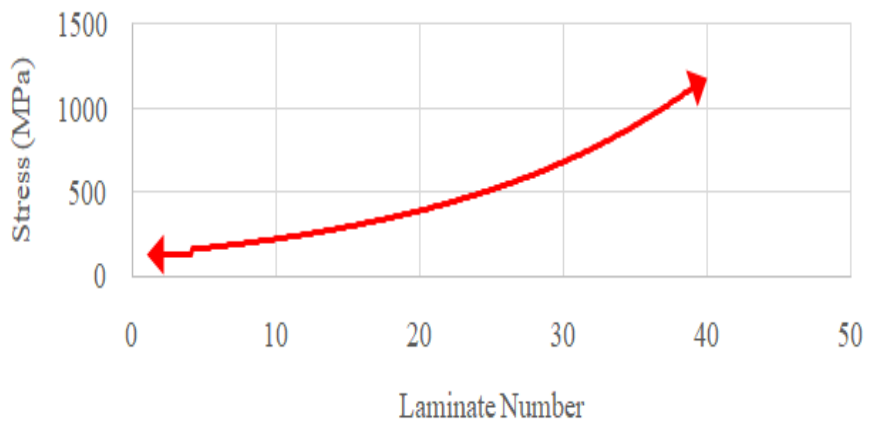

Figure 8: Stress Trend Line Approximation.

\subsection{Stress VS. Strain Behavior}

The stress vs. strain behavior of the composite with different laminate orientations is very unpredictable. The scattered plot for this behavior is shown below.

Figure 9 shows are plotted using the result table obtained from the parametric analysis. The closest approximation to this behavior is a sixth order polynomial $(\mathrm{y}=6.51 \mathrm{E}-19 \mathrm{x} 6-2.85 \mathrm{E}-15 \mathrm{x} 5+4.81 \mathrm{E}-12 \mathrm{x} 4-3.89 \mathrm{E}-09 \mathrm{x} 3+1.54 \mathrm{E}-06 \mathrm{x} 2-$ $2.49 \mathrm{E}-04 \mathrm{x}+1.96 \mathrm{E}-02)$

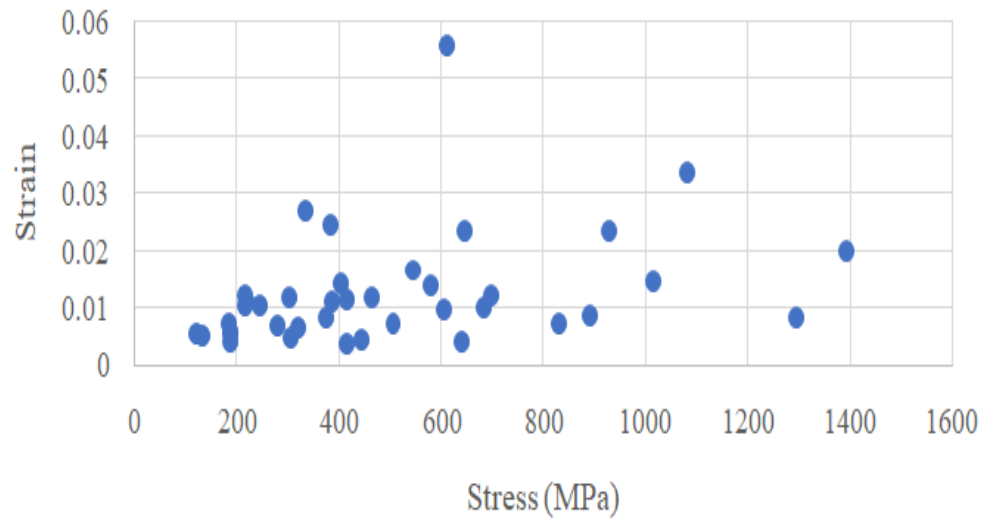

Figure 9: Stress vs. Strain Data Points from Parametric Analysis. 


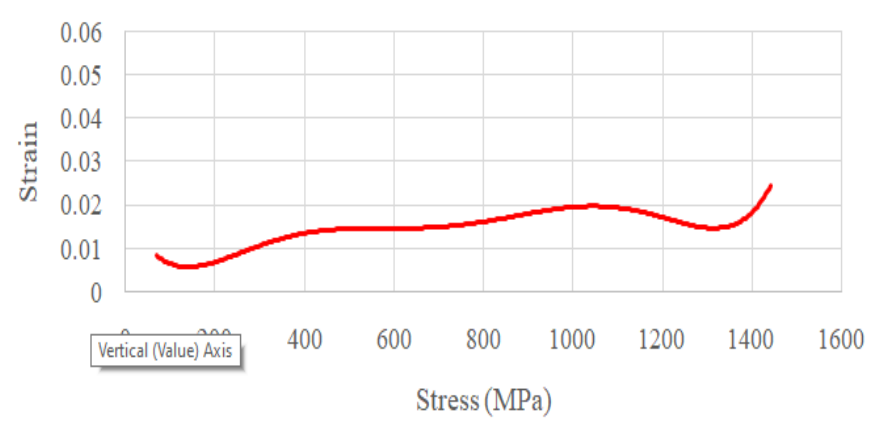

Figure 10: Stress vs. Strain Trend Line.

\subsection{Stress Variation of the Optimized Laminate}

The optimized laminate stack up obtained from the parametric analysis is the stack up of the design point 36 (DP36) from the parametric result table. The average induced stress of the laminate from this stack up is 119.75 with an Inverse Reserve Factor of 0.4026 .

The variation of stress in different layers of the optimized laminate is shown $\left(0^{0}, 30^{0}, 54.7^{0}, 45^{0}, 60^{0}, 90^{0},-54.7^{0}\right.$, $\left.0^{0},-54.7^{0}, 90^{\circ}, 60^{\circ}, 45^{\circ}, 54.7^{0}, 30^{\circ}, 0^{\circ}\right)$. The maximum stress induced is mainly located between the two supports and except for $0^{0} 30^{\circ}$ fiber angles. Form this we can say that these angles can be used for making components in which the stress induced in the cylindrical part is high. For the hemispherical dome $30^{\circ}$ and $-54.7^{0}$ orientations are not suggested because of the high stresses induced.

Figure 11 shows the blue line indicates the stress induced in the first seven layers of the laminate and the orange line indicates the stress induced in the last seven layers of the laminate. The stress induced in the central layer of the laminate with $0^{0}$ fiber orientation is $171.4 \mathrm{MPa}$. From the graph we can observe that symmetry exists in the variation of stress for the layers above and below the $0^{0}$-fiber orientation layer. But the inner layers experience more stress when compared to the outer layers.

The stress propagation in this optimized laminate is shown below

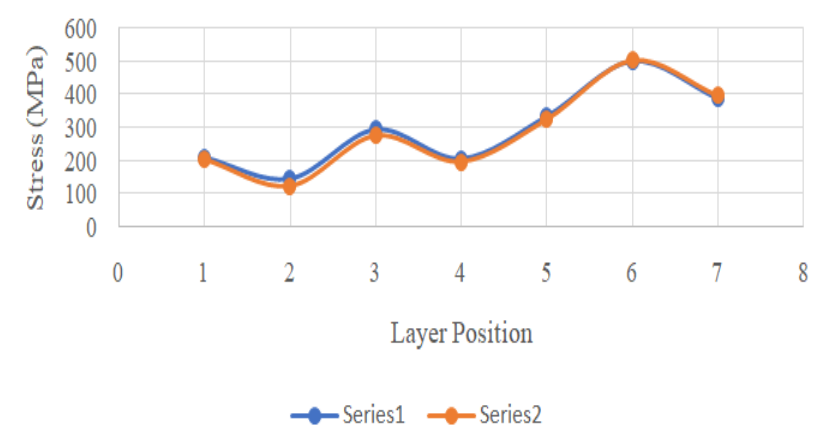

Figure 11: Stress Propagation in Optimized Laminate.

\section{CONCLUSIONS}

- The Stresses in each layer in the pressure vessel is obtained.

- The Polynomial equation for the Stress Vs Strain graph is obtained and was nonlinear.

- The Parametric analysis is done on the composite pressure vessel by considering the orientation angles as inputs 
and stress value as output.

- The optimum value for orientation angle is obtained.

- The strength to weight ratio of composite pressure vessel is significantly higher when compared to conventional materials.

- $\quad$ The Inverse reverse factor is found to be 0.68

- The pressure vessel can bear up to 10MPa with ease and avoid any catastrophic failure.

\section{REFERENCES}

1. King, D. \& Inderwildi, Oliver \& Carey, C. (2009). Advanced aerospace materials: past, present and future. Aviat Environ (Paris Airshow Spec Ed). 3. 2227.

2. Kesavarao, Yenda, Ch Ramakrishna, and AineelkamalArji. "Stress Analysis of Laminated Graphite/Epoxy Composite Plate Using FEM." International Journal of Mechanical Engineering (IJME) 4 (2015): 5.

3. Youssef Kannan, Armin. (2017). Ansys Tutorial for ACP (Full composite tutorial in ANSYS). 10.13140/RG.2.2.31473.53604.

4. Khandan, Rasoul, Noroozi, Siamak, Sewell, Philip, Vinney, John, and Ramazani, Mohammad Reza. "Optimum Design of Fibre Orientation Angles in Composite Laminate Plates for Minimum Thickness." Proceedings of the ASME 2010 International Mechanical Engineering Congress and Exposition. Volume 12: Processing and Engineering Applications of Novel Materials. Vancouver, British Columbia, Canada. November 12-18, 2010. pp. 193-200. ASME.

5. Al-Shammari, Mohsin Abdullah, and Muhannad Al-Waily."Theoretical and numerical vibration investigation study of orthotropic hyper composite plate structure." International Journal of Mechanical \& Mechatronics Engineering IJMMEIJENS 14.06 (2014).

6. P. V. Lakshmi Prasanna, M. Lakshmi Sramika, P. Seema Rani, 2016, Estimation of Optimum Fiber Angle of Composite Reinforced Tube using FEA, INTERNATIONAL JOURNAL OF ENGINEERING RESEARCH \& TECHNOLOGY (IJERT) Volume 05, Issue 11 (November 2016), http://dx.doi.org/10.17577/IJERTV5IS110109.

7. Tomar, Archit, and Dheer Singh. "Modelling and Analysis of a Chassis Frame by Using Carbon Fiber and E-Glass Epoxy as Composite Material: A Comparative Study." International Research Journal of Engineering and Technology 3.04 (2016): 23950072

8. Al-Waily, Muhannad."Experimental and numerical vibration study of woven Reinforcement composite laminated plate with delamination effect." International Journal of Mechanical Engineering (IJME), IASET, 2 (5) (2013). 

